\title{
ROLE OF THE SOCIAL DIMENSION IN THE SUSTAINABILITY-ORIENTED MAINTENANCE OPTIMIZATION OF BRIDGES IN COASTAL ENVIRONMENTS
}

\author{
IGNACIO J. NAVARRO ${ }^{1}$, VÍCTOR YEPES ${ }^{2} \&$ JOSÉ V. MARTÍ $^{2}$ \\ ${ }^{1}$ Department of Construction Engineering, Universitat Politècnica de València, Spain \\ ${ }^{2}$ Institute of Concrete Science and Technology (ICITECH), Universitat Politècnica de València, Spain
}

\begin{abstract}
The recently established Sustainable Development Goals recognize the importance of infrastructures for achieving a sustainable future. Along their long-lasting life cycle, infrastructures generate a series of impacts, the reduction of which has been one of the main focus of researchers' attention in past years. The optimization of maintenance intervals of structures, such as bridges, has aroused the attention of the civil engineering sector, since most of the impacts of infrastructures occur during the operational phase. Thus, bridges are currently designed to attend the economic and environmental impacts derived from maintenance activities. However, the social pillar of sustainability is usually neglected in those analyses. Since no universally accepted methodology does yet exist for its consistent evaluation, the social dimension is not effectively included in the life cycle assessments of infrastructures. This communication evaluates the life cycle impacts of alternative concrete bridge deck designs in a maintenance-demanding environment near shore. Reliability-derived maintenance intervals are first optimized by minimizing the economic and environmental impacts. In a second stage of the analysis, the social dimension is included in the optimization process and results are compared. Optimization results from these combined assessments are obtained applying the multi-criteria decision-making technique AHP-TOPSIS. The present paper demonstrates how the inclusion of the social dimension may lead to different, more sustainably-oriented optimal maintenance strategies. The three-dimensional approach applied here has resulted in other alternatives being preferred to those derived from the conventional assessment that considers the economic and environmental perspectives. Such findings support the idea that holistic life cycle assessments are required for sustainable designs of infrastructures and that more efforts are urgently needed to integrate the social dimension in sustainability assessments of structures.
\end{abstract}

Keywords: life cycle assessment, bridges, maintenance, reliability, social impacts, sustainable design, sustainability, corrosion, multi-criteria decision making, AHP.

\section{INTRODUCTION}

The conventional approach for the design of infrastructures such as bridges consists of finding that particular geometry that best fits the budgetary restrictions existing at the time of constructing the structure, while complying with the requirements of strength and functionality requested by the existing codes [1]-[3]. During the last decades, the scientific community has put great effort in the analysis of the economic impacts derived throughout the entire service life of structures, thus assessing structural designs from a life cycle perspective [4]-[6]. Indeed, the maintenance has revealed itself as a critical source of economic impacts along time, conditioning the design of infrastructures in maintenance demanding environments [7], [8].

Despite such perspective change, the recently established Sustainable Development Goals claim for a new and even more profound paradigm shift in the way structures are conceived. In the past recent times, research has been conducted on the evaluation of the environmental impacts associated to the service life of infrastructures [9], [10]. The inclusion of the 
environmental dimension in the economic assessments performed to date has allowed designers to find solutions that fit better the sustainable future the society desires. Studies have been conducted to analyze the optimality of design geometries [11] and maintenance strategies [12], [13]. However, an appropriate sustainable design requires the simultaneous consideration of each of the three dimensions on which sustainability relies, namely economy, environment, but also society as well. To date, less attention has been paid to the assessment of the societal impacts related to the design of infrastructures [14], [15], and bridges in particular [16].

The present communication aims to analyze how the inclusion of social aspects in the life cycle sustainability assessment of bridges in aggressive environments can condition both the selection of materials, as well as the maintenance strategies to be followed, leading to more sustainable solutions if compared to those obtained through environmental and economic assessments. The analysis of the life cycle impacts on each of the three sustainability dimensions is performed here following ISO 14040 for environmental life cycle assessment. Such methodology has been applied to a particular case study of an existing bridge located near shore. The life cycle performance of six alternative designs to the currently existing one are evaluated under each of the three dimensions of sustainability. AHP-TOPSIS technique is used to evaluate the life cycle results assuming two design scenarios, namely the consideration of economy and environment, and the simultaneous consideration of each of the three sustainability dimensions. For each alternative, the optimal reliability-based maintenance interval is calculated.

\section{RESEARCH METHODOLOGY}

\subsection{Life cycle assessment}

The present study focuses on a hypothetical prestressed concrete bridge deck located in Vilanova de Arousa, Galicia (Spain). The bridge is located in a coastal environment, and has a continuous box-girder deck which is $2.5 \mathrm{~m}$ deep and $12 \mathrm{~m}$ wide. The baseline design (called REF hereafter) is assumed to have a passive reinforcement amount of $100 \mathrm{~kg} / \mathrm{m}^{3}$, with a concrete cover of $40 \mathrm{~mm}$. This design is based on a concrete mix with a cement content of $350 \mathrm{~kg} / \mathrm{m}^{3}$, and a water to cement ratio of 0.40 , according to national standards [17].

Six alternative designs are studied which provide better durability performance in chloride-laden environments as the one assumed here. As a first alternative (alternative $\mathrm{W} / \mathrm{C} 35$ hereafter), the water/cement ratio of the reference concrete mix is reduced to 0.35 , so as to increase the concrete cover resistance against chloride diffusivity. Other alternatives are evaluated which enhance the performance of the baseline design against chloride penetration by providing denser concretes. These consist of adding $10 \%$ silica fume, $20 \%$ fly ash or $10 \%$ styrene-butadiene latex (alternatives SF10, FA20, and PMC10, respectively) to the reference concrete mix. The durability of concrete structures in coastal environments can also be improved by using corrosion-resistant steels instead of the conventional carbon steel reinforcement. A design alternative considering stainless steel reinforcement (INOX hereafter) is analysed here. At last, the performance of hydrophobic surface treatments applied to the deck surface (HYDRO hereafter) is also evaluated. These treatments are used to prevent corrosion by impeding the chloride ingress into concrete. Table 1 presents the concrete mixes considered for each design. It shall be noted that the concrete mix of the reference alternative s shared also by alternatives INOX and HYDRO. 
Table 1: Concrete mixes assumed for each design.

\begin{tabular}{|c|c|c|c|c|c|}
\hline Mix component & REF & SF10 & FA20 & PMC10 & W/C35 \\
\hline Cement $\left(\mathrm{kg} / \mathrm{m}^{3}\right)$ & 350 & 280 & 329 & 350 & 350 \\
\hline Water $\left(1 / \mathrm{m}^{3}\right)$ & 140 & 140 & 140 & 140 & 122.5 \\
\hline Gravel $\left(\mathrm{kg} / \mathrm{m}^{3}\right)$ & 1017 & 1017 & 1017 & 1017 & 1037 \\
\hline Sand $\left(\mathrm{kg} / \mathrm{m}^{3}\right)$ & 1068 & 1129 & 1086 & 1068 & 1095 \\
\hline Fly ash $\left(\mathrm{kg} / \mathrm{m}^{3}\right)$ & - & - & 70 & - & - \\
\hline Silica fume $\left(\mathrm{kg} / \mathrm{m}^{3}\right)$ & - & 35 & - & - & - \\
\hline Latex $\left(\mathrm{kg} / \mathrm{m}^{3}\right)$ & - & - & - & 70 & - \\
\hline Plasticiser $\left(\mathrm{kg} / \mathrm{m}^{3}\right)$ & 5.3 & 4.2 & 4.9 & - & 7 \\
\hline
\end{tabular}

This life cycle oriented analysis considers as a functional unit a $1 \mathrm{~m}$ long section of the above described bridge deck, providing terrestrial connection over a 100 year time span. A "gate-to-grave" approach is assumed here, including the impacts derived from every activity required to provide the functionality described. Therefore, the system under analysis covers from the resource extraction and production of the different construction materials associated to each design alternative under evaluation, up to the demolition activities at the end of life of the bridge. Fig. 1 shows the boundaries of the product system analysed. Considering the comparison-oriented scope of the analysis, processes that are common to every alternative are excluded, as they result in identical impacts [18].

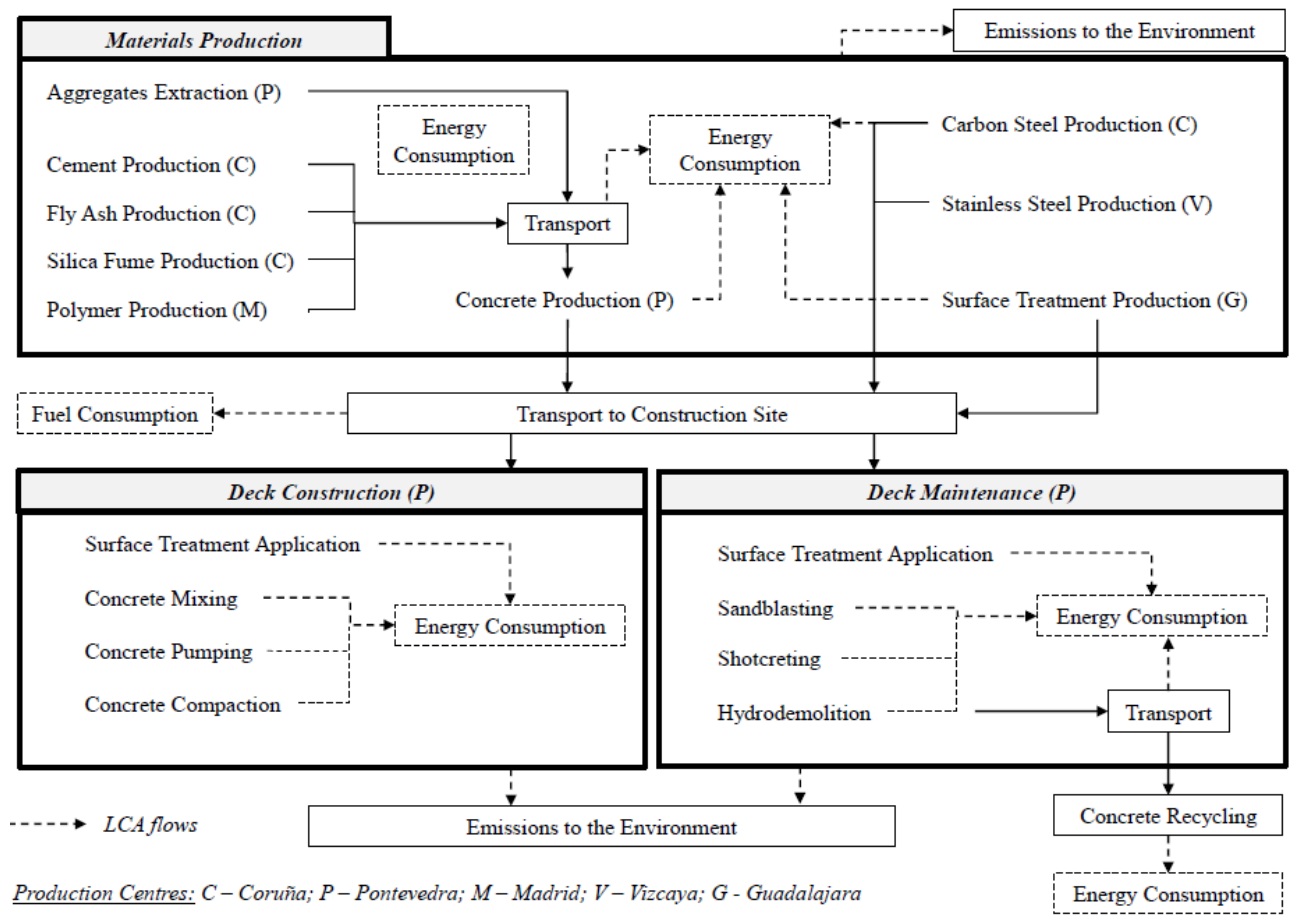

Figure 1: Product system boundaries. 


\subsubsection{Reliability-based maintenance demand}

The system under analysis also includes the maintenance activities required by each of the alternatives depending on their durability performance against chlorides. Such durability depends first on the properties of the reinforcing steel and on the chloride concentration required to trigger corrosion. This content is called critical chloride content $\left(\mathrm{C}_{\mathrm{cr}}\right)$. The time needed by chlorides to reach such concentration $\mathrm{C}_{\mathrm{cr}}$ at the rebars depth depends on the properties of the concrete cover. To evaluate the advance of the chloride front in concrete over time, a two-dimensional version of the Fickean model proposed in Fib Bulletin 34 [19] is used. The chloride concentration $\mathrm{C}$ at any time $t$ and at any depth in both $x$ and $y$ directions of the cross-section under analysis is thus given by:

$$
\mathrm{C}(\mathrm{x}, \mathrm{y}, \mathrm{t})=C_{s} \cdot\left(1-\operatorname{erf} \frac{x}{2 \sqrt{D_{0, x^{\prime}} \cdot t_{0}{ }^{\alpha} \cdot t^{1-\alpha}}} \cdot \operatorname{erf} \frac{y}{2 \sqrt{D_{0, y} \cdot t_{0}{ }^{\alpha} \cdot t^{1-\alpha}}}\right),
$$

where $x$ and $y$ are measured from the exposed cross-section surface inwards (in mm), $t$ is the time of evaluation (in years), $C_{\mathrm{s}}$ is the chloride concentration at the concrete surface (in $\mathrm{wt} \% /$ binder), $D_{0}$ is the chloride diffusion coefficient ( $\mathrm{mm}^{2} /$ year), and $\operatorname{erf}($.$) is the Gaussian$ error function. In accordance to [17], a surface chloride concentration $C_{\mathrm{s}}=0.0033$ and an age factor $\alpha=0.5$ are considered here. The reference time $t_{0}$ is considered to be 28 days, i.e. $t_{0}=$ 0.0767 years. The particular values for the durability parameters of each design alternative are based on [20] and are summarized in Table 2. On the basis of these values, the failure probability at any time $t$ shall be evaluated by means of Monte Carlo simulations, considering that failure occurs when the chloride concentration exceeds the critical chloride content at the rebar depth, namely $40 \mathrm{~mm}$ (standard deviation is $2 \mathrm{~mm}$ ). Maintenance is mandatory at the time when the reliability $\beta(\mathrm{t})$ reaches $\beta_{\lim }=1.3$ [21]. Maintenance is optimized by finding the particular time $\mathrm{t} \leq \mathrm{t}_{\text {lim }}$ for which the resulting life cycle negative impacts are minimized.

Table 2: Durability characterization of each design.

\begin{tabular}{|l|c|c|c|c|}
\hline \multirow{2}{*}{ Design alternative } & \multicolumn{2}{|c|}{$\mathrm{D}_{0}\left(\mathrm{x} 10^{-12} \mathrm{~m}^{2} / \mathrm{s}\right)$} & \multicolumn{2}{c|}{$\mathrm{C}_{\text {crit }}(\%)$} \\
\cline { 2 - 5 } & Mean & Std. dev. & Mean & Std. dev. \\
\hline REF & 8.90 & 0.90 & 0.60 & 0.10 \\
\hline SF10 & 1.23 & 0.17 & 0.60 & 0.03 \\
\hline FA20 & 4.65 & 0.35 & 0.60 & 0.10 \\
\hline PMC10 & 6.51 & 0.55 & 0.60 & 0.10 \\
\hline INOX & 8.90 & 0.90 & 5.00 & 0.94 \\
\hline W/C35 & 5.80 & 0.47 & 0.60 & 0.10 \\
\hline HYDRO & 6.88 & 0.60 & 0.60 & 0.10 \\
\hline
\end{tabular}

\subsubsection{Impact assessment}

The assessment of the economic life cycle impacts considers two impact categories, namely the costs associated to the bridge deck construction, and the discounted costs derived from the maintenance activities required by each alternative over time. In this assessment, a social discount rate $d=2 \%$ has been chosen.

The evaluation of the life cycle impacts of the considered deck designs on the environment is performed following the ReCiPe 2008 methodology. This methodology translates 18 different environmental impact subcategories, such as eutrophication, acidification, or ozone 
layer depletion, into three endpoint indicators that are simpler to interpret, namely damage to human health, damage to the ecosystems and resources depletion. More information on the environmental and economic assessment shall be found in [12].

At last, social impacts are assessed following the impact methodology suggested in [16]. This indicator-based methodology considers four main social impact categories to be associated to bridge infrastructures un Spain, namely the impact related to workers and employment generation, the impact on the economic development of the regions affected by the economic activities associated to construction and maintenance of the deck, the impacts on the bridge deck users, measured in terms of travel delays or reduction of travel safety derived from maintenance activities, and the impacts on the public opinion and aesthetical perception of the bridge site.

\subsubsection{Inventory analysis}

The data on costs associated to construction materials and activities involved in each of the different design options along their respective life cycles have been gathered from national construction-specific databases. Unitary costs of each foreground concept are presented in Table 3. The location of each production centre is specified in Fig. 1.

Table 3: Production and installation costs of materials.

\begin{tabular}{|l|c|c|c|c|c|c|}
\hline Product & Cement & Concrete & Additives & Steel & $\begin{array}{c}\text { Surf. } \\
\text { treat. }\end{array}$ & Installation \\
\hline Baseline Concrete & 30.7 & 31.7 & - & - & - & 31.6 \\
\hline W/C35 - Concrete & 30.7 & 32.4 & - & - & - & 36.7 \\
\hline FA20-Concrete & 43.4 & 34.6 & - & - & - & 31.1 \\
\hline SF10- Concrete & 36.9 & 72.4 & - & - & - & 30.1 \\
\hline HMP10-Concrete & 46.1 & 31.7 & 173.6 & - & - & 24.3 \\
\hline Carbon steel & - & - & - & 0.9 & - & 0.4 \\
\hline Stainless steel & - & - & - & 4.9 & - & 0.4 \\
\hline Hydro. treatment & - & - & - & - & 2.9 & 1.6 \\
\hline Cover hydrodemolition & - & - & - & - & - & 27.7 \\
\hline $\begin{array}{l}\text { Reinforcement } \\
\text { preparation }\end{array}$ & - & - & - & - & - & 16.0 \\
\hline
\end{tabular}

The inventory data required for the environmental assessment of each of the materials involved in the alternatives under study have been gathered from the environmental database Ecoinvent 3.2. This information has been complemented with particular energy demand values associated with the activity processes related to material production and installation activities, as shown in Table 4.

Data required for the social assessment of each design has been collected from national databases, namely the Spanish National Statistics Institute and the Spanish Tax Office (Table 5). 
Table 4: Demand values related to activity processes, based on [20].

\begin{tabular}{|l|c|c|}
\hline Process & Energy demand & Activity performance \\
\hline Concrete mixing & $75 \mathrm{~kW}$ & $7.2 \mathrm{~min} / \mathrm{m}^{3}$ \\
\hline Emulsion mixing & $0.025 \mathrm{kWh} / \mathrm{kg}$ & \\
\hline Hydrophobic surface treating & $1.3 \mathrm{~kW}$ & $1201 / \mathrm{h}$ \\
\hline Hydrodemolition & $0.75 \mathrm{~kW}$ & $0.6 \mathrm{~m}^{3} / \mathrm{h}$ \\
\hline Sandblasting & $2.31 \mathrm{fuel} / \mathrm{h}$ & $13.2 \mathrm{~m}^{2} / \mathrm{h}$ \\
\hline Shotcreting & $26.5 \mathrm{~kW}$ & $18 \mathrm{~m}^{3} / \mathrm{h}$ \\
\hline
\end{tabular}

Table 5: Social inventory data of involved production centres, based on [16].

\begin{tabular}{|l|c|c|c|c|c|}
\hline Product & Pontevedra & A Coruña & Vizcaya & Madrid & Guadalajara \\
\hline Unemployment rate & 16.8 & 13.9 & 12.5 & 12.4 & 14 \\
\hline $\begin{array}{l}\text { Men's unemployment } \\
\text { rate }\end{array}$ & 15 & 12.5 & 11.8 & 11.6 & 12.2 \\
\hline $\begin{array}{l}\text { Women's } \\
\text { unemployment rate }\end{array}$ & 19.1 & 15.8 & 13.4 & 13.3 & 16.7 \\
\hline Salary & $19.6^{1} ; 14.3^{2}$ & 19.6 & 20.3 & 32 & 23.6 \\
\hline Men's salary & 18.8 & 20.9 & 28.2 & 27.4 & 21.9 \\
\hline Women's salary & 14.2 & 15.9 & 20.1 & 20.1 & 16 \\
\hline Mean regional salary & 16.7 & 18.6 & 24.6 & 24 & 19.4 \\
\hline Accident rate & $84^{2} ; 76^{3}$ & $95^{4} ; 73^{3}$ & 94 & 33 & 54 \\
\hline $\begin{array}{l}\text { Maximum national } \\
\text { accident rate }\end{array}$ & $111^{2} ; 100^{3}$ & $129^{4} ; 100^{3}$ & 129 & 55 & 55 \\
\hline $\begin{array}{l}\text { Minimum national } \\
\text { accident rate }\end{array}$ & $60^{2} ; 54^{3}$ & $70^{4} ; 54^{3}$ & 70 & 29 & 29 \\
\hline $\begin{array}{l}\text { Gross domestic } \\
\text { product }\end{array}$ & $3210^{1} ; 1532^{2}$ & 2695 & 4908 & 14030 & 872 \\
\hline
\end{tabular}

Industry sector. ${ }^{2}$ Construction sector. ${ }^{3}$ Extraction industry. ${ }^{4}$ Metallurgic industry. ${ }^{5} \mathrm{Chemical}$ industry.

\section{RESULTS AND DISCUSSION}

\subsection{LCA-LCCA combined approach}

Here, results are shown regarding a conventional assessment of the different bridge deck designs under study, considering solely the environmental and economic dimensions of sustainability. The criteria included in this first assessment are the five criteria associated to these two dimensions, as presented above. From these criteria, two are related to the economic dimension, namely construction costs, and maintenance and end of life costs, and three are related to the impacts on the environment, namely damage to human health, damage to ecosystems and resources availability. A group of experts has been consulted to determine the weights to be associated to each criterion by using the AHP technique. The resulting weights are shown in Table 6 . 
Table 6: AHP criteria weights considering environment and economy.

\begin{tabular}{|l|c|}
\hline Criterion & Relative relevance \\
\hline Construction costs & $8.22 \%$ \\
\hline Maintenance and end of life costs & $5.72 \%$ \\
\hline Damage to human health & $25.71 \%$ \\
\hline Damage to ecosystem & $30.11 \%$ \\
\hline Resource availability & $30.25 \%$ \\
\hline
\end{tabular}

Considering the above presented criteria weights, multicriteria decision making technique TOPSIS has been used to evaluate the resulting life cycle sustainability of each design taking into consideration the economic and environmental dimensions. Fig. 2 shows the results of the two life cycle assessments, as well as of the TOPSIS-derived sustainability score. Results are presented for the maintenance interval that maximizes the sustainability score, which is shown in brackets under each alternative identification.

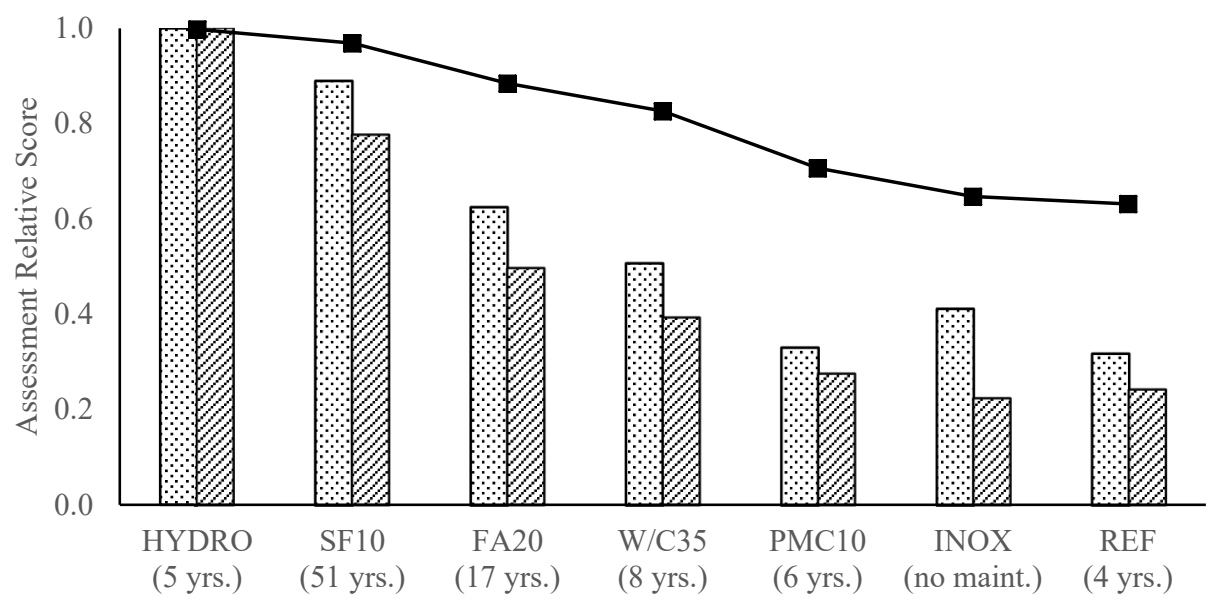

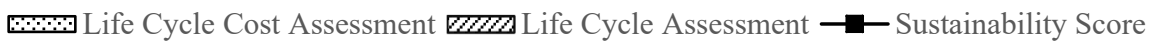

Figure 2: Conventional sustainability assessment results considering the environmental and economic dimensions.

Note that results are normalized so that the best assessment result scores 1 . It is observed that the preferred design consists of the baseline bridge deck design where the surface is protected periodically by a hydrophobic treatment. This has resulted in the best results, both in the environmental and in the economic dimension individually. On the contrary, the worst life cycle performance is that associated to the baseline design. Such design shows bad durability and derives in excessive maintenance demands along the analyzed 100 year service life. Such maintenance demand results in great environmental impacts derived from the material needs, as well as in great economic costs associated to each maintenance activity, where concrete cover is required to be adequately replaced. It is remarkable that the 
alternative using stainless steel rebars, which does not incur in any maintenance costs along its service life, presents poor sustainability performance. This is due to the high environmental impacts associated to the production of stainless steel, as well as to the high costs associated to this material.

Hydrophobic treatment, although requiring a reapplication every 5 years, is very competitive in terms of costs. In addition, such reapplication does not require from the production of additional concrete for the replacement of the concrete cover, which remains unaltered along time.

\subsection{Sustainability-oriented approach}

Here, results are presented including in the sustainability assessment of the design alternatives under study the social impacts derived along their respective life cycles. Consequently, besides the aforementioned five economic and environmental criteria, four additional social criteria are considered, namely the social impacts on workers, on the economic regional development of the involved production centres, on the users of the infrastructure and on the public opinion of the local community at the construction site. The group of experts has been asked to restate their judgements emitted in the previous assessment so as to consider the social dimension of sustainability as well. The resulting criteria weights are presented in Table 7.

Table 7: AHP criteria weights considering environment and economy.

\begin{tabular}{|l|c|}
\hline Criterion & Relative relevance \\
\hline Construction costs & $6.23 \%$ \\
\hline Maintenance and end of life costs & $4.33 \%$ \\
\hline Damage to human health & $19.47 \%$ \\
\hline Damage to ecosystem & $22.80 \%$ \\
\hline Resource availability & $22.90 \%$ \\
\hline Workers & $3.77 \%$ \\
\hline Economic development of regions & $3.60 \%$ \\
\hline Users & $9.54 \%$ \\
\hline Public opinion & $7.36 \%$ \\
\hline
\end{tabular}

TOPSIS technique has been applied considering the new criteria weights so as to evaluate the life cycle sustainability performance of each of the seven alternative designs assumed. The assessment results, as well as the maintenance interval that maximizes the sustainability score of each alternative, are presented in Fig. 3.

Considering the three sustainability dimensions simultaneously, it shall be observed that the design performing best along its life cycle is the one based on the use of concrete with an addition of 10\% silica fume (SF10). This solution, although scoring less than the design based on surface treatments on the economic and environmental assessments individually, has a much balanced response when adding the social dimension. Consequently, the sustainability score of the design SF10 is $11 \%$ greater than the sustainability score of the alternative HYDRO. The need of a periodical reapplication of surface treatments every 5 years incurs in negative social impacts on the public opinion, the aesthetics of the bridge site and on the 


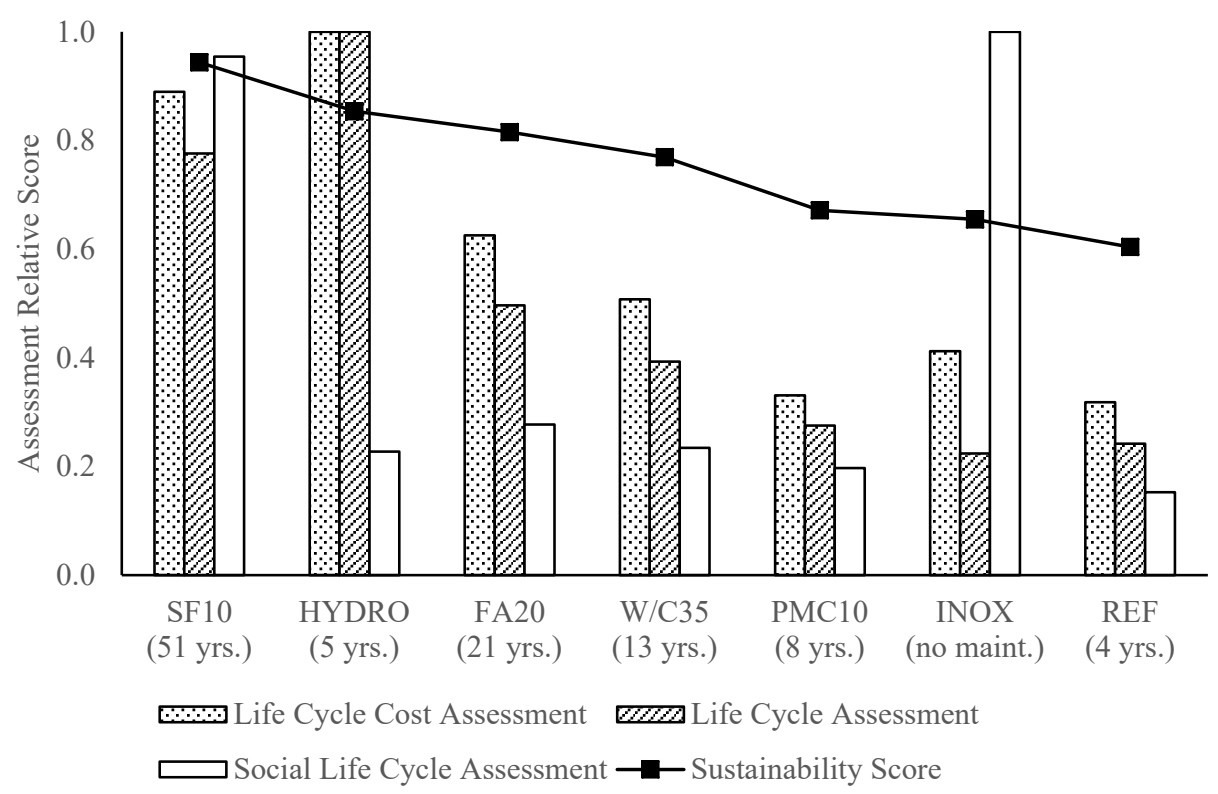

Figure 3: Sustainability assessment results considering all three dimensions of sustainability.

infrastructure users, thus resulting in the bad social scores that can be observed in Fig. 3 for the alternative HYDRO. On the contrary, the maintenance-free alternative based on stainless steel rebars (INOX) derives in the highest social scores, as the public opinion and the users of the infrastructure are benefitted from the structure to remain unaffected along its entire service life.

From the results presented in Fig. 3, it is also observed that the optimum maintenance interval for some of the designs, namely FA20, W/C35 and PMC10 has changed when including the social dimension in the assessment. In particular, it is observed how these optimal intervals have increased. This is due to the fact that the social positive impacts on users and on the public opinion of the local community are benefited from reduced affection of the structure along time. The greater AHP weights for these two criteria are almost 2 to 3 times greater than the relevance given to the other two social impact categories, namely workers and economic development of regions, which are benefited by higher maintenance demands. Here, to reduce the affection to the infrastructure is preferred to the generation of employment and economic inflows in the different production centres.

\section{CONCLUSIONS}

The present communication shows that the conventional sustainability assessments of infrastructures based on the sole consideration of the economic and environmental dimensions of sustainability, are not enough to properly catch the holistic scope of sustainability.

This study results in the alternative based on the addition of silica fume (SF10) to perform better than the alternative that would be preferred if conducting a conventional sustainability assessment, namely the use of hydrophobic surface treatments (HYDRO). SF10 scores 11\% 
greater than the conventionally preferred alternative HYDRO in the assumed coastal environment. The presented results could change if the social context of the production centres affected by the infrastructure social system were different. However, although the results shown here are highly site-specific, they allow us to conclude that the inclusion of social aspects can derive in significantly different, more sustainable alternatives than those arising from conventional sustainability assessments.

\section{ACKNOWLEDGEMENTS}

The authors acknowledge the financial support of the Spanish Ministry of Economy and Competitiveness, along with FEDER funding (Project: BIA2017-85098-R).

\section{REFERENCES}

[1] Yepes, V., Martí, J.V., García-Segura, T. \& González-Vidosa, F., Heuristics in optimal detailed design of precast road bridges. Archives of Civil and Mechanical Engineering, 17, pp. 738-749, 2017.

[2] García-Segura, T., Yepes, V. \& Frangopol, D.M., Multi-objective design of posttensioned concrete road bridges using artificial neural networks. Structural and Multidisciplinary Optimization, 56(1), pp. 139-150, 2017.

[3] Martí, J.V., González-Vidosa, F., Yepes, V. \& Alcalá, J., Design of prestressed concrete precast road bridges with hybrid simulated annealing. Engineering Structures, 48, pp. 342-352, 2013.

[4] Soliman, M. \& Frangopol, D.M., Life-cycle cost evaluation of conventional and corrosion-resistant steel for bridges. Journal of Bridge Engineering, 20(1), 2015.

[5] Barone, G. \& Frangopol, D.M., Life-cycle maintenance of deteriorating structures by multi-objective optimization involving reliability, risk, availability, hazard and cost. Structural Safety, 48, pp. 40-50, 2014.

[6] Navarro, I.J., Yepes, V. \& Martí, J.V., Life cycle cost assessment of preventive strategies applied to prestressed concrete bridges exposed to chlorides. Sustainability, 10(3), p. 845, 2018.

[7] Frangopol, D.M. \& Soliman, M., Life-cycle of structural systems: recent achievements and future directions. Structure and Infrastructure Engineering, 12(1), pp. 1-20, 2016.

[8] Safi, M., Sundquist, H. \& Karoumi, R., Cost-efficient procurement of bridge infrastructures by incorporating life-cycle cost analysis with bridge management systems. Journal of Bridge Engineering, 20(6), 2015.

[9] Navarro, I.J., Yepes, V., Martí, J.V. \& González-Vidosa, F., Life cycle impact assessment of corrosion preventive designs applied to prestressed concrete bridge decks. Journal of Cleaner Production, 196, pp. 698-713, 2018.

[10] Penades-Pla, V., Martí, J.V., García-Segura, T. \& Yepes, V., Life cycle assessment: A comparison between two optimal post-tensioned concrete box-girder road bridges. Sustainability, 9(10), p. 1864, 2017.

[11] García-Segura, T. \& Yepes, V., Multiobjective optimization of post-tensioned concrete box-girder road bridges considering cost, $\mathrm{CO}_{2}$ emissions, and safety. Engineering Structures, 125, pp. 325-336, 2016.

[12] Navarro, I.J., Martí, J.V. \& Yepes, V., Reliability-based maintenance optimization of corrosion preventive designs under a life cycle perspective. Environmental Impact Assessment Review, 74, pp. 23-34, 2019.

[13] García-Segura, T., Yepes, V., Frangopol, D.M. \& Yang, D.Y., lifetime reliabilitybased optimization of post-tensioned box-girder bridges. Engineering Structures, 145, pp. 381-391, 2017. 
[14] Sierra, L.A., Pellicer, E. \& Yepes, V., Social sustainability in the life cycle of Chilean public infrastructure. Journal of Construction Engineering and Management, 142(5), 2016.

[15] Sierra, L.A., Yepes, V., García-Segura, T. \& Pellicer, E., Bayesian network method for decision-making about the social sustainability of infrastructure projects. Journal of Cleaner Production, 176, pp. 521-534, 2018.

[16] Navarro, I.J., Yepes, V. \& Martí, J.V., Social life cycle assessment of concrete bridge decks exposed to aggressive environments. Environmental Impact Assessment Review, 72, pp. 50-63, 2018.

[17] Fomento, EHE-08 Instrucción del Hormigón Estructural, Ministerio de Fomento: Madrid, Spain, 2008.

[18] Martınez-Blanco, J., Lehmann, A., Muñoz, P., Anton, A., Traverso, M., Rieradevall, J. \& Finkbeiner, M., Application challenges for the social life cycle assessment of fertilizers within life cycle sustainability assessment. Journal of Cleaner Production, 69, pp. 34-48, 2014.

[19] Fib Bulletin 34, Model code for service life design. Fib: Lausanne, 2006.

[20] Navarro, I.J., Yepes, V. \& Martí, J.V., Sustainability assessment of concrete bridge deck designs in coastal environments using neutrosophic criteria weights. Structure and Infrastructure Engineering, 2019.

[21] Nogueira, C.G., Leonel, E.D. \& Coda, H.B., Reliability algorithms applied to reinforced concrete structures durability assessment. Revista IBRACON de Estruturas e Materiais, 5(4), pp. 440-450, 2012. 